\title{
Characterization and isolation of stem cell- enriched human hair follicle bulge cells
}

\author{
Manabu Ohyama, ${ }^{1}$ Atsushi Terunuma, ${ }^{1}$ Christine L. Tock, ${ }^{1}$ \\ Michael F. Radonovich, ${ }^{2}$ Cynthia A. Pise-Masison, ${ }^{2}$ Steven B. Hopping, ${ }^{3}$ \\ John N. Brady, ${ }^{2}$ Mark C. Udey, ${ }^{1}$ and Jonathan C. Vogel1 \\ ${ }^{1}$ Dermatology Branch and 2Laboratory of Cellular Oncology, Center for Cancer Research, National Cancer Institute, \\ $\mathrm{NIH}$, Bethesda, Maryland, USA. ${ }^{3}$ The Center for Cosmetic Surgery, Washington, DC, USA.
}

\begin{abstract}
The human hair follicle bulge is an important niche for keratinocyte stem cells (KSCs). Elucidation of human bulge cell biology could be facilitated by analysis of global gene expression profiles and identification of unique cell-surface markers. The lack of distinctive bulge morphology in human hair follicles has hampered studies of bulge cells and KSCs. In this study, we determined the distribution of label-retaining cells to define the human anagen bulge. Using navigated laser capture microdissection, bulge cells and outer root sheath cells from other follicle regions were obtained and analyzed with cDNA microarrays. Gene transcripts encoding inhibitors of WNT and activin/bone morphogenic protein signaling were overrepresented in the bulge, while genes responsible for cell proliferation were underrepresented, consistent with the existence of quiescent noncycling KSCs in anagen follicles. Positive markers for bulge cells included CD200, PHLDA1, follistatin, and frizzled homolog 1, while CD24, CD34, CD71, and CD146 were preferentially expressed by nonbulge keratinocytes. Importantly, $\mathrm{CD}^{200}{ }^{+}$cells $\left(\mathrm{CD} 200^{\mathrm{h}} \mathrm{CD} 24^{\mathrm{lo}} \mathrm{CD} 34^{\mathrm{lo}} \mathrm{CD} 71^{\mathrm{lo}} \mathrm{CD} 146^{\mathrm{lo}}\right)$ obtained from hair follicle suspensions demonstrated high colony-forming efficiency in clonogenic assays, indicating successful enrichment of living human bulge stem cells. The stem cell behavior of enriched bulge cells and their utility for gene therapy and hair regeneration will need to be assessed in in vivo assays.
\end{abstract}

\section{Introduction}

Hair follicles are self-renewing structures that cycle and reconstitute themselves throughout life because they contain keratinocyte stem cells (KSCs) (1, 2). In 1990, Costarelis et al. (3) demonstrated that, in rodent hair follicles, label-retaining cells (LRCs), the slowly cycling keratinocytes that represent KSCs (3-7), localize to a region of the outer root sheath (ORS) surrounding the rodent hair shaft termed the "bulge." The bulge approximates the attachment site for the arrector pili muscle and marks the bottom of the permanent portion of the follicle during cycling (8). Accumulated evidence subsequently confirmed that, in rodents, the bulge is the repository of multipotent stem cells that support hair follicle cycling and repopulate interfollicular epidermis and sebaceous epithelium $(6,7,9-11)$.

Although several lines of evidence have suggested that the human bulge also provides a niche for KSCs $(12,13)$, anatomic boundaries, biochemical distinctiveness, and global gene expression pattern are ill defined. In contrast to the bulge of murine follicles, which can easily be outlined as a discrete projection, the human adult anagen bulge does not possess distinctive morphological fea-

Nonstandard abbreviations used: ANGPTL2, angiopoietin-like 2; BMP, bone morphogenic protein; BNC, bulge-negative cocktail; CDC2, cell division cycle 2, G1 to S and G2 to M; DCT, dopachrome tautomerase; DIO2, deiodinase, iodothyronine, type II; DKK3, Dickkopf homolog 3; EDNR, endothelin receptor; FST, follistatin; FZD1, frizzled homolog 1; GPM6B, glycoprotein M6B; KRT15, keratin 15; KSC, keratinocyte stem cell; LCM, laser capture microdissection; LRC, label-retaining cell; MAS, Affymetrix Microarray Suite; N-LCM, navigated LCM; ORS, outer root sheath; PHLDA1, pleckstrin homology-like domain, family A, member 1; PRC1, protein regulator of cytokinesis 1; TOP2A, topoisomerase (DNA) II alpha $170 \mathrm{kDa}$; WIF1, WNT inhibitory factor 1 .

Conflict of interest: The authors have declared that no conflict of interest exists.

Citation for this article: $J$. Clin. Invest. 116:249-260 (2006).

doi:10.1172/JCI26043. tures $(12,13)$. In addition, although genes that are upregulated in mouse bulge cells have been identified, including the cell-surface marker CD34 $(7,10,14)$, genes whose expression is upregulated in human bulge keratinocytes remain to be determined. Moreover, the elegant transgenic approaches that allow viable murine bulge cells to be isolated $(7,10)$ cannot be applied to humans. Although several groups have attempted to isolate human bulge cells by manual $(15,16)$ or laser capture microdissection (LCM) (17), accurate and efficient isolation of human bulge cells has not yet been reported. Consequently, isolation of living human bulge cells required development of new methods.

Exploring the biology of enriched KSC populations requires ready access to living bulge cells. Multipotent and highly prolific bulge cells may also be an important source of stem cells for cutaneous regenerative medicine (18). For gene therapy purposes, ex vivo gene delivery to KSC-enriched bulge cells may facilitate long-lasting gene expression and correction of congenital skin and hair disorders $(19,20)$. Finally, a better understanding of human bulge cells may provide important insights into the biology of stem cells of other human epithelial tissues (21), as well as epithelial cancer stem cells.

The goal of the present study was to delineate the biological distinctiveness of human hair follicle bulge cells by analyzing bulge global gene expression patterns. Identification of surface proteins that might constitute candidate stem cell markers was a specific focus of our data analysis. In this study, we developed methods to precisely identify the anatomical location of the human bulge region and then collected bulge ORS cells by navigated LCM (N-LCM). The global gene expression profile of bulge ORS cells was determined by microarray analysis and compared with that of other defined ORS cell subpopulations to identify genes that were differentially expressed in the bulge 
A

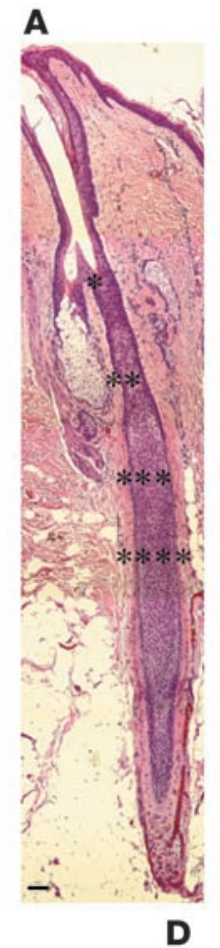

B
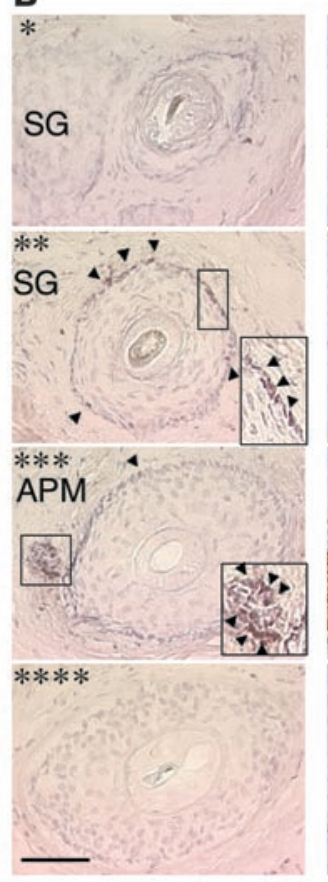

KRT15+
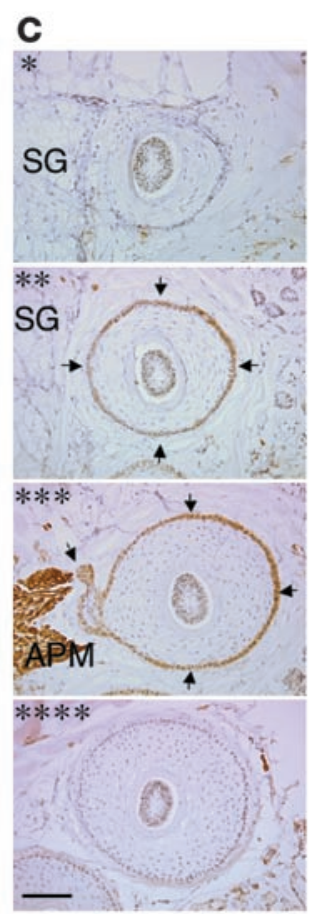

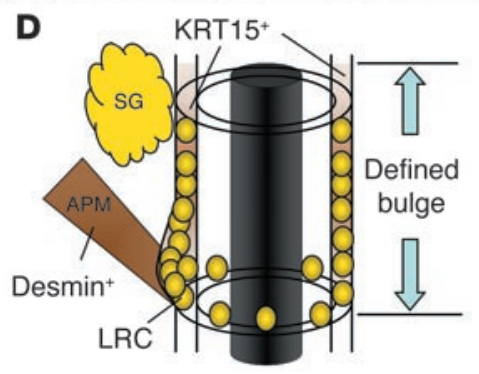

area. By combining positive and negative selection markers identified on bulge cells by microarray analysis and confirmed by immunohistochemistry, we enriched living human bulge cells and assessed their biological behavior in an in vitro colony-forming KSC assay. This report describes the systematic transcriptional profiling of human bulge cells and the first demonstration to our knowledge of directed enrichment of putative human hair follicle stem cells.

\section{Results}

Localization of LRCs defines the buman anagen hair follicle bulge region. Our initial goal was to isolate the KSC-enriched cell population from the bulge area of human hair follicles and compare global gene expression patterns to those of other defined regions of human follicles. Since slow-cycling LRCs are believed to represent stem cells and to be located in the bulge area of rodent follicles $(3,5-7)$, we used the distribution of LRCs in human follicles to define the boundaries of the human bulge. For the detection of LRCs in human hair follicles, human scalp samples were transplanted onto the backs of nude mice and labeled by continuous BrdU administration (13). After completing the 4- to 6-week labeling and 10- to 12 -week washout periods, xenografts were harvested, and serial transverse (horizontal) sections were prepared to accurately localize LRCs. LRCs were detected in the outermost

\section{Figure 1}

Human anagen hair follicle bulge is defined by the distribution of LRCs. (A) Vertical section of human hair follicle. (B) In xenografted human scalp tissue, BrdU-labeled LRCs (arrowheads) were predominantly detected in the outermost layer of ORS between the insertion point of the arrector pili muscle (APM) and the sebaceous gland (SG) level. (C) The distribution of LRCs in the human hair follicle defines the bulge and can be detected immunohistochemically (arrows) by the cocktail of antibodies containing C8/144B (cross-reactive to KRT15 in ORS) and D33 (anti-desmin). Asterisks in the transverse sections in both $\mathbf{B}$ and C indicate their locations within the vertical hair follicle section in A. (D) Schema of the defined human hair follicle bulge. Scale bars: $50 \mu \mathrm{m}$.

layer of the ORS above the arrector pili muscle insertion point and below the sebaceous gland (Figure 1, A and B). Thus, the location of the sebaceous gland defines the upper border and the arrector pili muscle insertion point defines the lower border of the human anagen bulge (Figure 1, B and D). We subsequently determined that the anatomical location of LRCs in human follicles could be defined in frozen sections using the $\mathrm{mAb}$ C8/144 (cross-reactive to keratin 15 [KRT15]) (13); the anti-desmin mAb D33, which detects the arrector pili muscle; and the location of the sebaceous gland (Figure 1, C and D). C8/144B stained KRT15 in the outermost layers of the ORS below the upper level of the sebaceous gland, but the staining did not always extend inferiorly to the arrector pili muscle insertion point (Figure 1D). Since LRCs were present in the ORS at the level of the arrector pili muscle insertion site in the xenografting study (Figure 1B), the anti-desmin mAb D33 was necessary to identify the insertion point and define the lower boundary of the human bulge (Figure 1C). For the purpose of this study, the human bulge corresponds to the KRT15+ ORS extending precisely from the region of the sebaceous gland to the arrector pili muscle insertion site (Figure 1D). Approximately $20 \%$ of ORS cells in the bulge region were LRCs.

Isolation of total RNA from bulge ORS cells and other well-defined regions using $N-L C M$. Immunohistochemical detection of BrdU in LRCs requires fixation and cellular permeabilization, and intact RNA cannot be accurately recovered from permeabilized LRCs for microarray analysis. To overcome this problem, human bulge cells and hair follicle cells from other well-defined regions (Figure 2A) were collected by an N-LCM approach from fresh frozen sections (22), and gene expression was analyzed by microarray analysis. Serial transverse sections of $5-\mathrm{mm}$ scalp punch biopsy specimens from healthy volunteers contained approximately $40-50$ anagen follicles per section. Since immunohistochemistry and quantitative recovery of intact RNA cannot be performed on the same section, every fifth serial frozen section was stained with C8/144B and D33 to determine which transverse sections contained bulge regions of anagen follicles. Only hair follicles with the characteristics described above were sampled. In addition, only intervening unstained sections that were known to contain bulge regions were used for N-LCM (Figure 2, B and C).

This approach allowed the maximum number of ORS cells to be isolated from each bulge on each slide. The standard method for the histopathological evaluation of follicles in human scalp by vertical sectioning would not have permitted N-LCM-microarray analysis because most follicles would be cut tangentially, with far fewer bulge ORS cells available for N-LCM isolation. This approach was also used to sample other anatomical regions from serial sections of the same follicle (Figure 2A). 
A

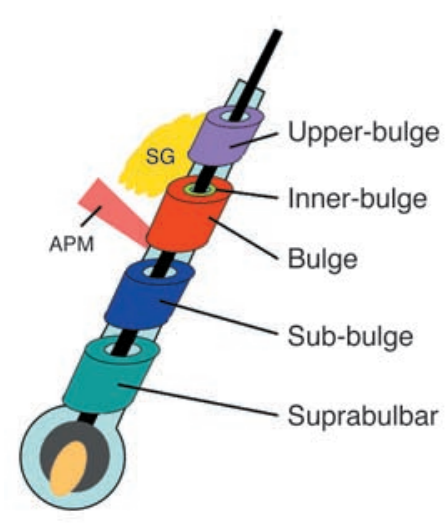

B

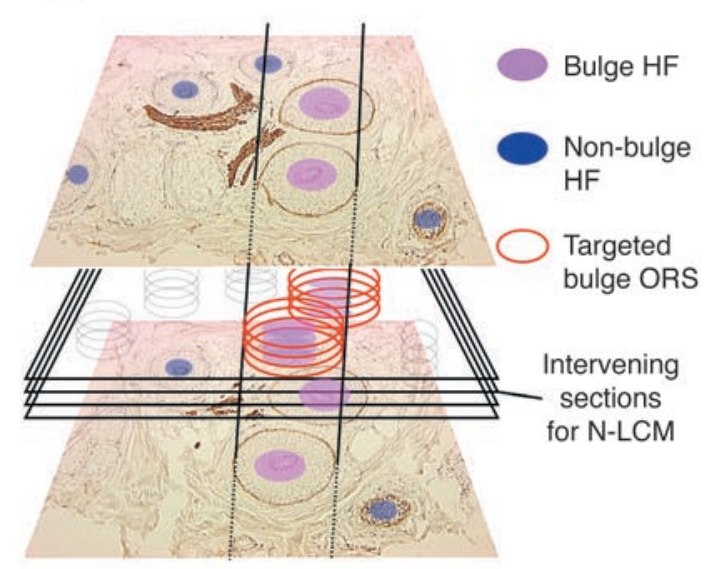

C

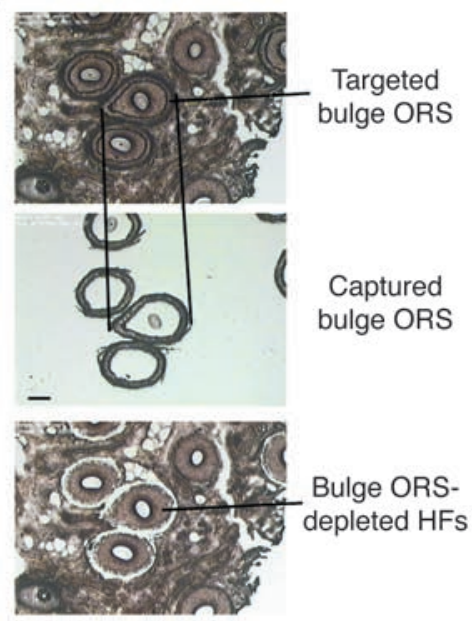

Figure 2

The N-LCM technique was used to isolate the defined bulge ORS and other ORS regions for microarray analysis. (A) N-LCM-targeted ORS regions. "Upper-bulge" represents ORS cells at the upper portion of bulge, while "bulge" represents the ORS cells constituting the main body of the bulge. (B) The N-LCM strategy to collect the defined bulge ORS was as follows: Every fifth transverse section was stained with C8/144B and D33 mAb. Only hair follicles with positive C8144B/D33 staining of the outermost layer of ORS and the arrector pili muscle on consecutive sections (pink follicles) were selected as bulge ORS LCM targets. (C) Successful N-LCM isolation of the defined bulge ORS from target follicles. Scale bar: $20 \mu \mathrm{m}$. HF, hair follicle.

In initial experiments, bulge ORS cells were isolated, and gene expression profiles were compared with those of the outermost layer of ORS cells just below the bulge (below the arrector pili muscle attachment; referred to as sub-bulge ORS hereafter) (Figure 2A). Three scalp biopsy specimens from different volunteers were processed, and total RNA (11.5-24.7 ng) was isolated from each N-LCM-captured ORS subset.

Micorarray data analysis and the confirmation of differential gene expression in bulge ORS at the protein level. Three pairs of bulge versus subbulge ORS GeneChips (Affymetrix HG-U133A; 22,283 probe sets) representing gene expression patterns in hair follicles from individual donors were analyzed. GeneChip data was of high quality, with $38.4 \% \pm 2.3 \%$ of transcripts detected as present on arrays (23). The average correlation coefficient within GeneChips representing individual subpopulations was $0.96 \pm 0.01$, indicating that the isolated cell populations were precisely defined and comparable.

To detect differentially expressed genes in the bulge area, we first analyzed and compared bulge versus sub-bulge ORS chips with 2 individual algorithms, Affymetrix Microarray Suite version 5.0 (MASv5.0) and dChip 1.3 (Supplemental Figure 1; supplemental material available online with this article; doi:10.1172/ JCI26043DS1). By MASv5.0 analysis, genes that were over- or underrepresented in all 3 pairs with at least 1.3 -fold change were selected for further analysis. Ninety genes (101 probe sets) were overrepresented in the bulge (Supplemental Table 1), while 110 genes (119 probe sets) were underrepresented (Supplemental Table 2). Using dChip analysis, a model-based expression index (MBEI) was calculated for each probe set (24), and differentially expressed genes were identified by comparison analysis. Using filtering criteria of fold changes in expression of at least 1.3 and $P$ values for paired $t$ test of less than 0.05 , we identified 78 genes ( 85 probe sets) that were overrepresented in bulge ORS (Supplemental Table 3) and 106 genes (112 probe sets) that were underrepresented (Supplemental Table 4). When MASv5.0 and dChip analyses were compared, 27 common genes ( 36 probe sets) were detected as overrepresented and 43 common genes ( 56 probe sets) were identified as underrepresented in the bulge ORS cells compared with the sub-bulge control ORS cells.

To identify transcripts that were selectively over- and underrepresented in bulge ORS cells and not in other anatomical hair follicle locations, we performed additional sets of N-LCM-microarray experiments to determine the global gene expression patterns in ORS cells from the 2 different locations within the bulge, the upper bulge and the bulge ORS, and 3 different non-bulge ORS locations: the sub-bulge ORS, the ORS above the bulb (suprabulbar ORS), and the inner layers of the ORS at the level of the bulge (inner-bulge ORS) (Figure 2A). By comparing gene expression profiles from these different ORS locations, genes that were specifically over- and underrepresented only in bulge ORS would be identified. For example, 5 transcripts that were overrepresented in bulge ORS compared with sub-bulge ORS were also highly expressed in inner-bulge ORS and, thus, were not specific to bulge ORS. After removing such genes from the compiled list, we concluded that 21 transcripts ( 28 probe sets) were overrepresented (Table 1) and 37 genes (48 probe sets) were underrepresented (Table 2 ) selectively in the human hair follicle anagen bulge ORS cells (Supplemental Table 5). Of note, KRT15 mRNA was overrepresented in bulge ORS cells, consistent with the increase in KRT15 protein detected in the region that we defined as the human anagen bulge (Table 1). The raw chip data files are available at http://www.ncbi.nlm.nih. gov/geo/query/acc.cgi?acc=GSE3419.

To determine whether our microarray data accurately predicted differences in protein expression, we performed immunohistochemistry and FACS analysis of human hair follicle samples and cells. Five proteins corresponding to overrepresented transcripts and 3 underrepresented transcripts (see Tables 1 and 2) were evaluated by immunohistochemical staining of transversely sectioned bulge and sub-bulge ORS regions of the same follicle. All 


\section{Table 1}

Genes selectively upregulated in the human anagen HF bulge

\begin{tabular}{|c|c|c|}
\hline Gene & $\begin{array}{l}\text { dChip } \\
\text { fold } \\
\text { change }\end{array}$ & $\begin{array}{c}\text { MAS } \\
\text { fold } \\
\text { change }\end{array}$ \\
\hline Trinucleotide repeat containing 9 (TNRC9) & 5.01 & 23.90 \\
\hline DIO2 & 4.71 & 5.71 \\
\hline PHLDA1 & 3.56 & 3.80 \\
\hline ANGPTL2 & 2.78 & 2.95 \\
\hline WIF1 & 2.77 & 5.72 \\
\hline Regulated in glioma $(R / G)$ & 2.48 & 1.72 \\
\hline Dickkopf homolog 3 (Xenopus laevis) (DKK3) & 2.45 & 4.65 \\
\hline $\begin{array}{l}\text { Calcium/calmodulin-dependent protein } \\
\text { kinase II (CaMKIINalpha) }\end{array}$ & 2.27 & 3.74 \\
\hline Dihydropyrimidinase-like 2 (DPYSL2) & 2.26 & 2.53 \\
\hline GPM6B & 2.12 & 1.95 \\
\hline Dihydropyrimidinase-like 3 (DPYSL3) & 2.08 & 2.37 \\
\hline $\operatorname{Decorin}(D C M)$ & 1.97 & 2.15 \\
\hline $\begin{array}{l}\text { Serine (or cysteine) proteinase inhibitor, } \\
\text { clade F, member } 1 \text { (SERPINF1) }\end{array}$ & 1.91 & 2.37 \\
\hline $\begin{array}{l}\text { Ca2+-dependent activator protein } \\
\text { for secretion } 2 \text { (CADPS2) }\end{array}$ & 1.87 & 2.12 \\
\hline Transforming growth factor, beta 2 (TGFB2) & 1.79 & 2.24 \\
\hline KRT15 & 1.75 & 2.07 \\
\hline Frizzled homolog 1 (Drosophila) (FZD1) & 1.58 & 1.54 \\
\hline $\begin{array}{l}\text { Nuclear factor of activated T cells, cytoplasmic, } \\
\text { calcineurin-dependent } 1 \text { (NFATC1) }\end{array}$ & 1.51 & 1.39 \\
\hline FST & 1.49 & 1.80 \\
\hline $\begin{array}{l}\text { Calmodulin } 1 \text { (phosphorylase kinase, delta) } \\
\text { (CALM1) }\end{array}$ & 1.4 & 1.36 \\
\hline $\begin{array}{l}\text { Dopachrome tautomerase (dopachrome delta- } \\
\text { isomerase, tyrosine-related protein 2) (DCT) }\end{array}$ & 1.34 & 3.62 \\
\hline
\end{tabular}

$\mathrm{HF}$, hair follicle.

6 overrepresented proteins (KRT15; frizzled homolog 1 [FZD1]; follistatin [FST]; Dickkopf homolog 3 [DKK3]; WNT inhibitory factor 1 [WIF1]; pleckstrin homology-like domain, family A, member1 [PHLDA1]) and 2 of 3 underrepresented proteins (CD146; endothelin receptor [EDNR]) were differentially expressed in the bulge ORS as compared with the sub-bulge ORS cells (Figure 3A). In addition, localization of positive staining for KRT15, FST, FZD1, and PHLDA1 on vertical sections correlated well with the RNA expression patterns defined in the second N-LCM experiment (Supplement Figure 2). KRT15-, FST-, and PHLDA1-positive staining was limited to the outermost ORS. KRT15 and FST staining extended beyond the defined bulge boundary, while PHLDA1 precisely localized to the defined bulge, providing the best single immunohistochemical marker for bulge ORS cells. FZD1 staining was globally expressed in the ORS but was most highly expressed in the defined bulge.

To facilitate isolation of living human bulge cells, we developed a methodology to efficiently generate single-cell suspensions from the mid-portions of isolated hair follicles (mid-follicle suspension; see Methods). In an attempt to validate microarray data, we performed FACS analysis of a fixed mid-follicle suspension with anti-KRT15 and -FST mAbs, since the anti-PHLDA1 $\mathrm{mAb}$ was not suitable for flow cytometry. As expected, KRT15and FST-positive populations were detected in fixed mid-follicle cell suspensions, and KRT15 ${ }^{\text {hiFST }}{ }^{\text {hi }}$ cells were present, suggesting they were derived from the bulge ORS (Figure 3B).
Immunohistochemical staining indicated that FST was more closely localized to the defined bulge (Supplemental Figure 2) than was KRT15. Consistent with this, fewer FST-positive cells were detected in mid-follicle suspensions than KRT15-positive cells. Thus, FST was selected as the best marker of bulge ORS cells in FACS studies of fixed mid-follicle suspensions.

Transcriptional profiles of the bulge ORS cells suggest a slow-cycling phenotype. Genes that were differentially expressed in human bulge regions were categorized with regard to their involvement in specific signaling pathways or biological processes (Figure 4). Overrepresented transcripts (Table 1) included those involved in WNT signaling (DKK3, WIF1, FZD1), activin/bone morphogenic protein (activin/BMP) signaling (FST), TGF- $\beta$ signaling (TGF $\beta 2$ ) and organogenesis (KRT15; decorin $[D C N]$; dopachrome tautomerase [DCT]; glycoprotein M6B [GPM6B]; dibydropyrimidinase-like 2 and 3 [DPSYSL2 and DPSYSL3]; serine (or cysteine) proteinase inbibitor, clade F, member 1 [SERPINF1]). A growth factor (angiopoietin-like 2 [ANG$P T L 2]$ ) and an enzyme for thyroid hormone activation (deiodinase, iodothyronine, type II [DIO2]) were also included. Of note, DKK3, WIF1, and FST are inhibitors of signaling, and TGF $\beta 2$ is a negative regulator of keratinocyte proliferation. Transcripts that were underrepresented included those corresponding to genes involved in cell division (tissue inbibitor of metalloproteinase 3 [TIMP3]; cell division cycle 2, G1 to $S$ and $G 2$ to $M$ [CDC2]; vav 3 oncogene [VAV3]; protein regulator of cytokinesis 1 [PRC1]; glypican 4 [GPC4]; syndecan 2 [SDC2]) or DNA replication/repair (ribonucleotide reductase $M 2$ polypeptide [RRM2]; flap structure-specific endonuclease 1 [FEN1]; topoisomerase (DNA) II alpha $170 \mathrm{kDa}$ [TOP2A]; thymidylate synthetase [TYMS]) (Table 2). These observations are compatible with enrichment of slow-cycling cells in the bulge of human anagen follicles and the concept that this region represents a stem cell niche.

Identification of cell-surface markers for buman hair follicle bulge cells. A major goal of our studies was to identify cell-surface markers for candidate stem cells in the human bulge. Putative bulge markers such as FST or PHLDA1 cannot be detected without fixation and thus cannot be used for enrichment and purification of living cells. The WNT receptor FZD1 was detected on human ORS and was overrepresented in the bulge (Figure $3 \mathrm{~A}$ and Supplemental Figure 2). Anti-FZD1 antibody reacted with $70 \%$ of all cells in fixed mid-follicle cell suspensions (Supplemental Figure 3A), and FZD ${ }^{\text {hi }}$ FST $^{\text {hi }}$ bulge cells were detected in $\mathrm{FZD}^{+}$cell populations (Supplemental Figure 3B). Unfortunately, anti-FZD1 antibody did not react with living ORS cells to a significant degree (Supplemental Figure 3C), suggesting that detection of the FZD1 epitope recognized by this antibody requires fixation. Thus, anti-FZD1 cannot be used for the isolation of living bulge cells.

We could not study other membrane proteins listed in Table 1, such as DIO2, GPM6B, and DCT, because appropriate antibodies were not readily available. Therefore, we reanalyzed the microarray data to identify additional candidate surface markers for bulge cells. Differentially expressed genes identified by MASv5.0 and dChip algorithms were analyzed separately to increase the likelihood that membrane proteins that were selectively overrepresented in bulge ORS could be detected. We focused on CD antigens, because well-characterized antibodies that are useful for analytical and preparative flow cytometry already exist. Using this strategy, CD59 and CD200 were selected as proteins of interest for further studies.

Analysis of microarray data using dChip software revealed that CD59 was highly expressed in both bulge and sub-bulge ORS, but 
Table 2

Genes selectively downregulated in the human anagen HF bulge

\begin{tabular}{|c|c|c|}
\hline Gene & $\begin{array}{l}\text { dChip } \\
\text { fold } \\
\text { change }\end{array}$ & $\begin{array}{l}\text { MAS } \\
\text { fold } \\
\text { change }\end{array}$ \\
\hline Cartilage oligomeric matrix protein (COMP) & -4.87 & -15.53 \\
\hline ANGPTL7 & -3.03 & -9.11 \\
\hline Tripartite motif-containing 9 (TRIM9) & -2.72 & -3.96 \\
\hline Aminolevulinate, delta-, dehydratase $(A L A D)$ & -2.62 & -4.35 \\
\hline Protocadherin $8(\mathrm{PCDH} 8)$ & -2.6 & -4.45 \\
\hline $\begin{array}{l}\text { Tissue inhibitor of metalloproteinase } 3 \\
\text { (Sorsby fundus dystrophy, } \\
\text { pseudoinflammatory) (TIMP3) }\end{array}$ & -2.39 & -3.55 \\
\hline $\begin{array}{l}\text { Nucleolar and spindle associated } \\
\text { protein } 1 \text { (NUSAP1) }\end{array}$ & -2.33 & -2.44 \\
\hline Platelet-derived growth factor C (PDGFC) & -2.3 & -2.81 \\
\hline $\begin{array}{l}\text { Solute carrier family 4, sodium bicarbonate } \\
\text { cotransporter, member } 7 \text { (SLC4A7) }\end{array}$ & -2.19 & -2.08 \\
\hline Laminin, beta 1 (LAMB1) & -2.11 & -2.47 \\
\hline Ets variant gene 5 (ets-related molecule) (ETV5) & -2.04 & -2.59 \\
\hline CDC2 & -2.04 & -2.73 \\
\hline $\begin{array}{l}\text { Phospholipase A2, group IVA } \\
\text { (cytosolic, calcium-dependent) (PLA2G4A) }\end{array}$ & -2.02 & -2.01 \\
\hline PRC1 & -1.88 & -1.64 \\
\hline Glypican 4 (GPC4) & -1.88 & -2.13 \\
\hline $\begin{array}{l}\text { Ribonucleotide reductase M2 } \\
\text { polypeptide (RRM2) }\end{array}$ & -1.87 & -1.91 \\
\hline Vav 3 oncogene (VAV3) & -1.83 & -1.71 \\
\hline ZW10 interactor (ZWINT) & -1.83 & -1.96 \\
\hline $\begin{array}{l}\text { Phosphorylase, glycogen; liver (Hers disease, } \\
\text { glycogen storage disease type VI) (PYGL) }\end{array}$ & -1.82 & -2.20 \\
\hline $\begin{array}{l}\text { Syndecan } 2 \text { (heparan sulfate proteoglycan 1, } \\
\text { cell surface-associated, fibroglycan) (SDC2) }\end{array}$ & -1.81 & -2.59 \\
\hline $\begin{array}{l}\text { Karyopherin alpha } 2 \text { (RAG cohort } 1, \\
\text { importin alpha 1) (KPNA2) }\end{array}$ & -1.79 & -1.97 \\
\hline $\begin{array}{l}\text { Protein phosphatase 1, regulatory } \\
\text { (inhibitor) subunit } 3 C \text { (PPPR } 3 C)\end{array}$ & -1.79 & -2.15 \\
\hline Flap structure-specific endonuclease 1 (FEN1) & -1.76 & -1.54 \\
\hline Retinoic acid induced $14(R A / 14)$ & -1.76 & -1.84 \\
\hline TOP2A & -1.76 & -6.10 \\
\hline $\begin{array}{l}\text { Solute carrier family } 1 \text { (glutamate/neutral } \\
\text { amino acid transporter), member } 4 \text { (SLC1A4) }\end{array}$ & -1.75 & -1.76 \\
\hline Fibroblast growth factor 18 (FGF18) & -1.68 & -3.72 \\
\hline Thymidylate synthetase (TYMS) & -1.65 & -1.49 \\
\hline Rac GTPase activating protein 1 (RACGAP1) & -1.64 & -2.07 \\
\hline pe XI, alpha 1 (COL11A1) & -1.63 & -2.28 \\
\hline $\begin{array}{l}\text { Melanoma cell adhesion molecule } \\
\text { (CD146) (MCAM) }\end{array}$ & -1.59 & -1.90 \\
\hline $\begin{array}{l}\text { Latent transforming growth factor } \\
\text { beta binding protein } 2 \text { (LTBP2) }\end{array}$ & -1.59 & -1.71 \\
\hline N-myc downstream regulated gene 1 (NDRG1) & -1.52 & -1.64 \\
\hline von Hippel-Lindau binding protein 1 (VBP1) & -1.42 & -1.40 \\
\hline Endothelin receptor type $B(E D N R B)$ & -1.4 & -1.94 \\
\hline Ras homolog enriched in brain $2(R H E B)$ & -1.39 & -1.56 \\
\hline $\begin{array}{l}\text { Solute carrier family } 7 \text { (cationic amino acid } \\
\text { transporter, y+ system), member } 1 \text { (SLC7A1) }\end{array}$ & -1.37 & -1.67 \\
\hline
\end{tabular}

its expression was 1.38-fold higher in bulge ORS than sub-bulge ORS (Supplemental Table 3). Using immunohistochemistry, we determined that CD59 was diffusely positive in ORS cells, although slight upregulation in bulge ORS was noticeable (Figure 5A). By FACS analysis, almost all viable FSThi bulge cells were also
CD59hi, but more than $80 \%$ of mid-follicle cells were also CD59+ (Figure 5A). Thus, CD59 has limited utility for selective enrichment of living bulge cells.

Expression of CD200 was determined to be increased 1.98-fold in bulge ORS as compared with sub-bulge ORS by MASv5.0 analysis (Supplemental Table 1). In addition, anti-CD200 mAb staining was restricted to the outermost layer of the ORS between the arrector pili muscle insertion point and the level of the sebaceous gland, corresponding precisely to our defined bulge (Figures 5B and $6 \mathrm{~A}$ ). However, the antibody also stained the companion layer between the upper bulge and suprabulbar level. Approximately $15-20 \%$ of living mid-follicle cells were CD200 positive in flow cytometry experiments, and $40 \%$ of all CD200hi cells also expressed the bulge marker FST (Figure 5B). Living CD200hi cells in midfollicle cell suspension were almost exclusively CD $45^{\text {lo }}$ and c-Kit ${ }^{\text {lo }}$, indicating they were neither bone marrow-derived cells nor melanocytes (Supplemental Figure 4, A and B). In addition, CD200hi mid-follicle cells expressed high levels of $\alpha 6$ integrin (Supplemental Figure 4C), a putative marker for KSCs (25). Thus, CD200 is a promising positive selector for living KSC-enriched bulge cells. Interestingly, approximately $1-2 \%$ of cells obtained from foreskins were $\mathrm{CD} 200^{\mathrm{hi}}$, and based on their $\mathrm{CD} 45^{\mathrm{lo}}$, $\mathrm{c}-\mathrm{Kit}^{\mathrm{lo}}$, and $\alpha 6$ integrin ${ }^{\mathrm{hi}}$ phenotype, a subpopulation of those cells was presumably keratinocytes (data not shown).

Identification of negative CD markers for human hair follicle bulge cells. Additional microarray analysis identified the CD antigens CD24, CD34, and CD71 as surface proteins that were overrepresented in non-bulge ORS (in addition to CD146 described above; Figure 3A). The utility of these $\mathrm{CD}$ proteins as selectors for bulge ORS was evaluated by immunohistochemistry and FACS analysis.

In MASv5.0 analysis, CD24 RNA expression was remarkably upregulated in the inner-bulge ORS compared with other ORS regions (Supplemental Figure 5). Immunohistochemical analysis confirmed that CD24 protein expression was highest in the non-bulge inner ORS (including the companion layer) and clearly spared the outermost layer of bulge ORS (Figure 6A). FACS analysis of mid-follicle suspensions demonstrated that CD24hi cells were distinct and nonoverlapping with FST ${ }^{\text {hi }}$ bulge ORS cells (Figure 6B). Thus, anti-CD24 negative selection might enrich for bulge ORS cells by selectively removing inner-layer ORS cells, including the CD200hi companion layer cells, from mid-follicle suspensions.

CD34 expression is low or absent in human bulge ORS cells (absent in 2 of 3 bulge chips) and is most highly expressed in the suprabulbar ORS region (Supplemental Figure 5). Consistent with this, anti-CD34 antibody stained suprabulbar ORS but did not stain bulge ORS cells at or above the level of the arrector pili muscle insertion (Figure 6A). Moreover, FACS analysis of mid-follicle suspensions demonstrated that CD34hi cells were FST ${ }^{\text {lo }}$, indicating they were not bulge cells (Figure 6B). The expression of CD34, a marker for hematopoietic stem cells in humans (but not in mice), has been reported in mouse bulge cells (14), and the absence of CD34 expression in human bulge has been previously noted (26). Our data indicated that CD34 is not present on bulge ORS cells in human hair follicles.

Decreased expression of CD71 was also detected by MASv5.0 analysis in 2 of 3 pairs of bulge versus sub-bulge ORS GeneChips. Additional GeneChip analysis demonstrated the highest level of expression of CD71 in suprabulbar ORS cells of human follicles (Supplemental Figure 5). By immunohistochemistry, CD71 was 
A

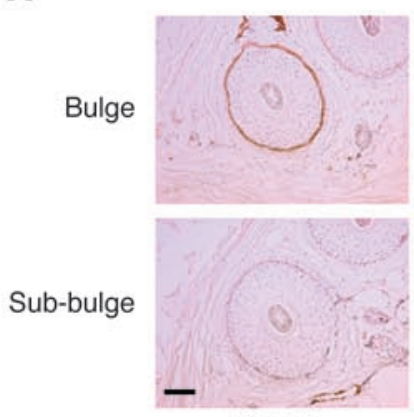

KRT15

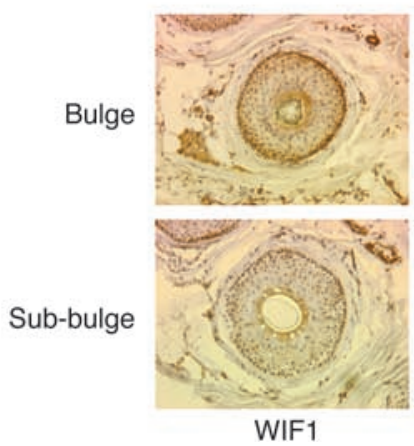

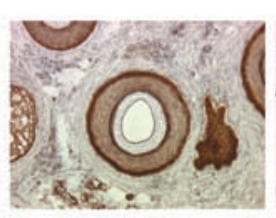
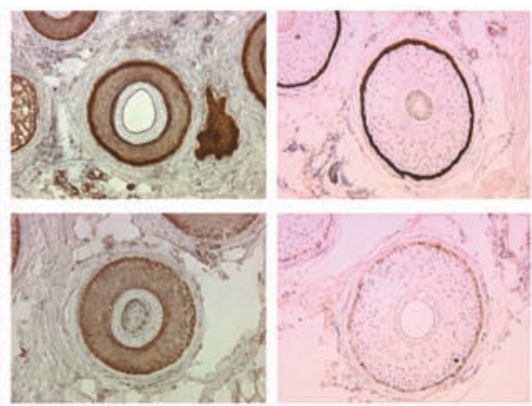

FZD1
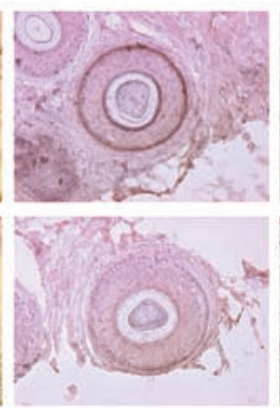

PHLDA1

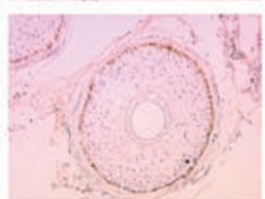

FST

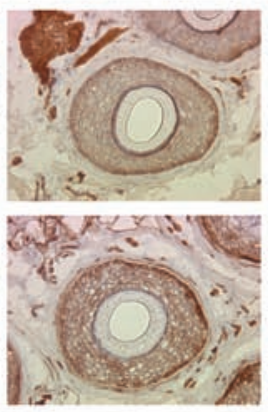

CD146

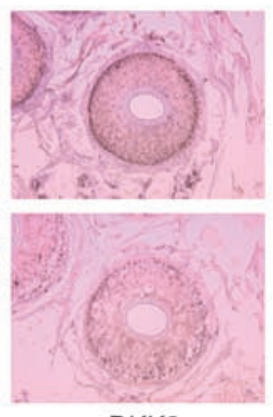

DKK3

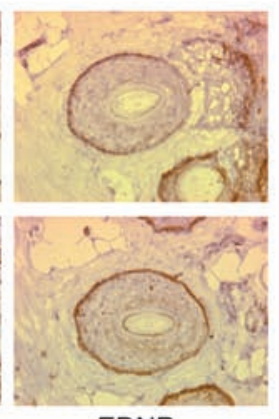

EDNR
B
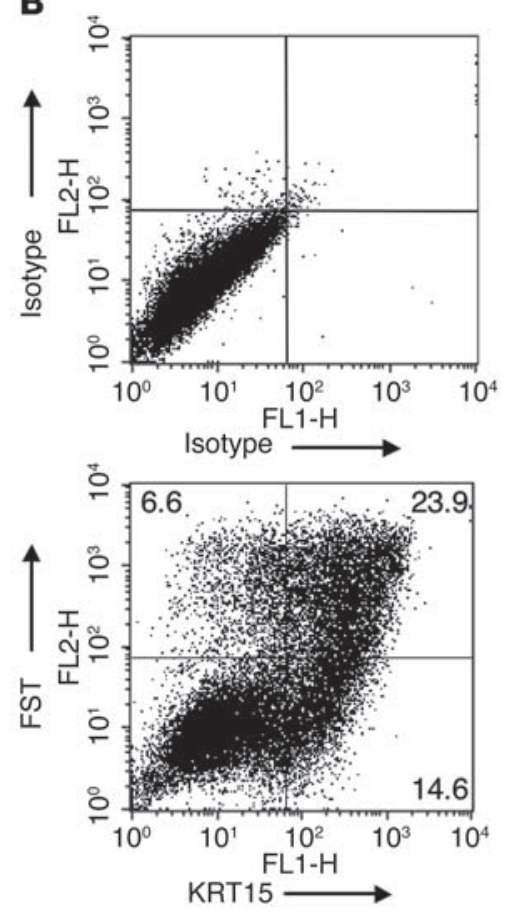

\section{Figure 3}

The differential expression of genes identified by microarray analysis was confirmed by immunohistochemistry and FACS analysis of human anagen hair follicle. (A) The transverse sections of the same individual hair follicle at the bulge and sub-bulge levels are shown for each gene. The antibodies against bulge ORS-upregulated gene products identified in microarray analysis (KRT15, FZD1, FST, DKK3, WIF1, PHLDA1) demonstrated stronger staining in the bulge ORS than sub-bulge ORS, while antibodies against the bulge ORS-downregulated gene products (melanoma adhesion molecule [CD146], EDNR) demonstrated intense staining in the sub-bulge ORS. Scale bar: $50 \mathrm{~mm}$. (B) Mid-follicle singlecell suspension was prepared from the mid-portion of individually isolated human hair follicles. Mid-follicle cells were fixed and stained with anti-FST and anti-KRT15 antibodies and analyzed with FACS. Consistent with microarray and immunohistochemistry data (see Supplemental Figure 2), fewer FST-positive cells were detected in mid-follicle suspensions than KRT15-positive cells. Subsequently, FST was used as the positive marker for human hair follicle bulge cells.

consistently expressed below the sub-bulge level of ORS (Figure 6A). In addition, CD71 $1^{\text {hi }}$ cells were FST ${ }^{\text {lo }}$ in FACS analysis of mid-follicle cells, indicating that $\mathrm{CD} 71^{\mathrm{hi}}$ cells are distinct from bulge ORS cells (Figure 6B). Reduced expression of CD71 along with high expression of $\alpha 6$ integrin has been reported to be a property of KSCs (25). Thus, CD71 could also be used as a negative marker for human bulge cells. Overrepresentation of CD146 in sub-bulge ORS had already been confirmed immunohistochemically (Figure 3A and Figure 6A), and, as expected, CD146 hi cells were FST ${ }^{\text {lo }}$ in FACS analyses of mid-follicle suspensions (Figure 6B).

Thus, a cocktail of CD24, CD34, CD71, and CD146 mAbs (bulgenegative cocktail $[\mathrm{BNC}]$ ) could be used to remove non-bulge cells in living mid-follicle suspension, including CD200 hi cells located in the companion layer (Figure 5B and Figure 7A).

Enrichment of living human bair follicle bulge cells by selection with positive and negative cell-surface markers. Human bulge cells have been reported to be highly proliferative in in vitro assays, with higher colony-forming efficiency than other follicle cells (16). To determine whether selection using the positive and negative markers described above could enrich for living human bulge cells with stem cell properties, cells were isolated from a mid-follicle cell suspension and analyzed for their colony-forming efficiency (Figure 7A).

On average, $26.4 \% \pm 2.0 \%$ of living mid-follicle cells were stained with BNC (Figure 7B). First, BNChi cells were removed from mid- follicle suspension by magnetic bead negative selection. Then, CD200 ${ }^{\text {hi }}$ cells were positively selected with magnetic beads. CD59, which is diffusely expressed in ORS cells (Figure 5A), was used as a control for the magnetic bead isolation procedure. Microscopic observation and FACS analysis demonstrated that isolated living $\mathrm{CD} 200^{\text {hi }} \mathrm{BNC}^{\text {lo }}$ cells were morphologically uniform, relatively compact, and round when compared with unfractionated mid-follicle or CD59hi cells (Supplemental Figure 6, $\mathrm{A}$ and $\mathrm{B})$. When identical numbers of living cells were seeded onto irradiated NIH 3T3 feeder layers, CD200 hi BNC lo cells formed significantly more colonies than mid-follicle cells (Figure 7C). The average increase observed in colony-forming efficiencies in $\mathrm{CD} 200^{\text {hi }} \mathrm{BNC}^{\text {lo }}$ cells as compared with mid-follicle cells was 2.0-fold (Figure 7D). These results demonstrate that hair follicle cells with a $\mathrm{CD} 200^{\mathrm{hi}} \mathrm{CD} 24^{\mathrm{lo}} \mathrm{CD} 34^{\mathrm{lo}} \mathrm{CD} 71^{\text {lo }} \mathrm{CD} 146^{\text {lo }}$ surface phenotype are enriched for cells with KSC properties.

\section{Discussion}

In this study, we localized LRCs in human anagen hair follicles, thereby defining the human bulge as an identifiable region of the ORS. Thereafter, we designed and implemented a strategy to isolate intact RNA from anatomically distinct regions (including the bulge ORS) by N-LCM of transverse sections of human scalp follicles. GeneChip microarray studies provided a 3D view of global 


\begin{tabular}{|c|c|}
\hline $\begin{array}{l}\text { Overrepresented in } \\
\text { bulge ORS }\end{array}$ & $\begin{array}{l}\text { Overrepresented in } \\
\text { sub-bulge ORS }\end{array}$ \\
\hline $\begin{array}{l}\text { WNT signaling } \\
\text { (DKK3, WIF1, FZD1) }\end{array}$ & $\begin{array}{l}\text { Cell division related } \\
\text { (TIMP3, CDC2, VAV3, }\end{array}$ \\
\hline $\begin{array}{l}\text { Activin/BMP signaling } \\
\text { (FST) }\end{array}$ & $\begin{array}{l}\text { PRC1, GPC4, SDC2) } \\
\text { DNA replication/repair }\end{array}$ \\
\hline $\begin{array}{l}\text { TGF } \beta \text { signaling } \\
\text { (TGF } \beta 2 \text { ) }\end{array}$ & TYMS) \\
\hline $\begin{array}{l}\text { Growth factor } \\
\text { (ANGPTL2) }\end{array}$ & $\begin{array}{l}\text { (ANGPTL7, PDGFC, } \\
\text { FGF18) }\end{array}$ \\
\hline $\begin{array}{l}\text { Hormone activation } \\
\text { (DIO2) }\end{array}$ & $\begin{array}{l}\text { Cell adhesion } \\
\text { (PCDH8, MCAM) }\end{array}$ \\
\hline $\begin{array}{l}\text { Antiapoptosis } \\
\text { (PHLDA1) }\end{array}$ & $\begin{array}{l}\text { ECM } \\
\text { (COMP, LAMB1, }\end{array}$ \\
\hline $\begin{array}{l}\text { Organogenesis } \\
\text { (KRT15, DCN, DCT, } \\
\text { GPM6M, DPYSL2, } \\
\text { DPYSL3, SERPINF1) }\end{array}$ & $\begin{array}{l}\text { COL11A1) } \\
\text { Transporter } \\
\text { (SLC1A4, SLC4A7, } \\
\text { SLC7A1, KPNA2) }\end{array}$ \\
\hline
\end{tabular}

gene expression patterns in human hair follicles, enabling identification of genes that were differentially and selectively expressed in the bulge ORS. To the best of our knowledge, this is the first description of global gene expression patterns in the KSC-enriched bulge and other regions of human follicles.

We are aware that although captured bulge ORS cells were enriched for LRCs, they do not represent a pure population of KSCs or even LRCs. Thus, some overrepresented genes may not be expressed in KSCs, and some genes that are selectively upregulated in KSCs may not have been detected. In addition, although keratinocytes predominate in the bulge, other cell types such as melanocyte stem cells (27) or Merkel cells (28) are also reported to reside in this area, and upregulation of a gene in bulge ORS could reflect highly elevated gene transcription in non-keratinocytes. For example, overrepresentation of DCT, a melanocyte lineage marker (29), in the bulge ORS may reflect presence of melanocyte stem cells or progenitor cells in the bulge region.

Immunohistochemical confirmation of differential protein expression predicted from microarray analyses validated our approach. Interestingly, subtle differences in mRNA expression resulted in marked differences in protein expression, a finding observed with regard to FST expression, for example. Recent microarray stud-

\section{Figure 5}

CD59 and CD200 are expressed in human anagen hair follicle, and CD200 is a positive cell-surface marker for the bulge ORS cells. (A) Immunohistochemically, CD59 was globally expressed at all ORS levels (vertical section) and upregulated in the bulge ORS (transverse sections). Scale bars: $50 \mu \mathrm{m}$. In FACS analysis, most mid-follicle cells were CD59+, and FSThi bulge cells were CD59+ (CD59 staining prior to fixation). (B) CD200 was preferentially expressed on the defined bulge ORS and the companion layer of human anagen hair follicles. Scale bars: $50 \mu \mathrm{m}$. By FACS analysis, CD200 was detectable on the mid-follicle cells, and approximately $40 \%$ of CD200hi cells were FST-double-positive bulge cells (CD200 staining before fixation).
A
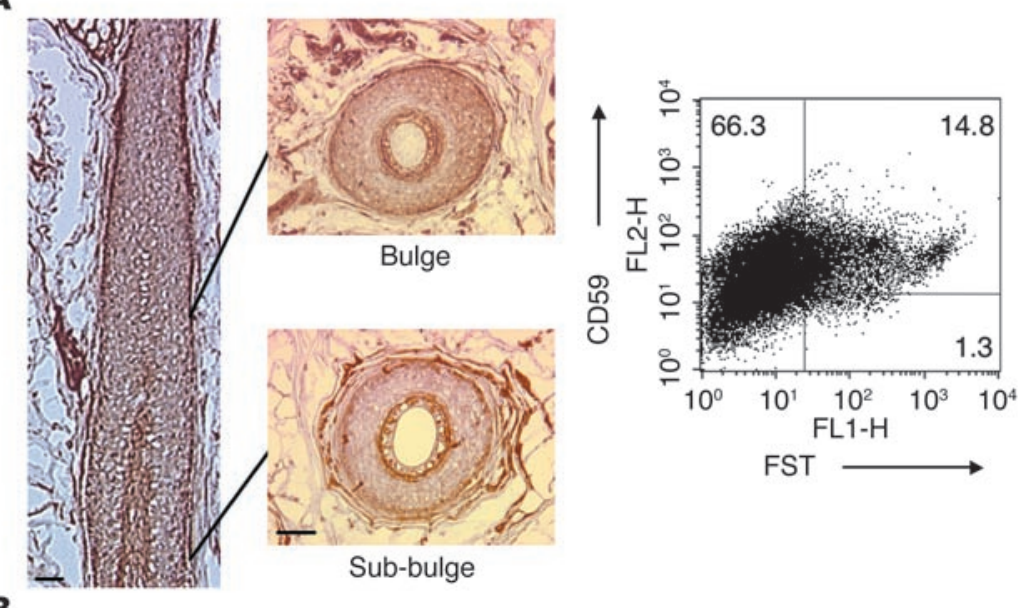

ies have employed quantitative RT-PCR to confirm the accuracy of microarray data. Considering that Affymetrix microarrays tend to underestimate gene expression differences $(10,30)$, validation of microarray data at protein level appears to be critical.

Transcripts overrepresented in the human bulge include genes of important biological pathways. The WNT signaling pathway plays an important role in hair follicle morphogenesis and cycling $(2,31)$, being activated at anagen onset $(32,33)$. Increased expression of the WNT inhibitors WIF1 and DKK3 in the bulge ORS during anagen is consistent with the anticipated quiescent state of hair follicle stem cells. Activin/BMP signaling and TGF $\beta / \mathrm{BMP}$ signaling pathways also regulate hair follicle development and cycling $(19,34,35)$. The activin/BMP signaling antagonist FST was selectively overrepresented in the bulge ORS. The blockade of activin signaling by FST may also promote maintenance of KSC quiescence.

Several genes upregulated in the bulge may promote survival of bulge ORS cells and KSCs. PHLDA1 was preferentially localized in the bulge ORS cells both at the mRNA and protein levels and has been reported to mediate the effects of insulin-like growth factor 1 and prevent apoptosis (36). The expression of DIO2, which was significantly elevated in bulge ORS (MASv5.0,
B

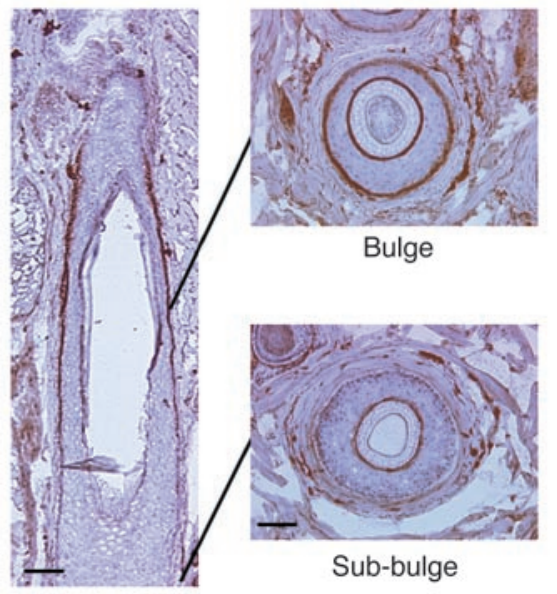

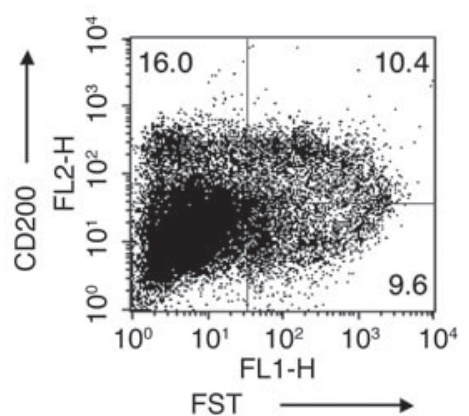




\section{A}

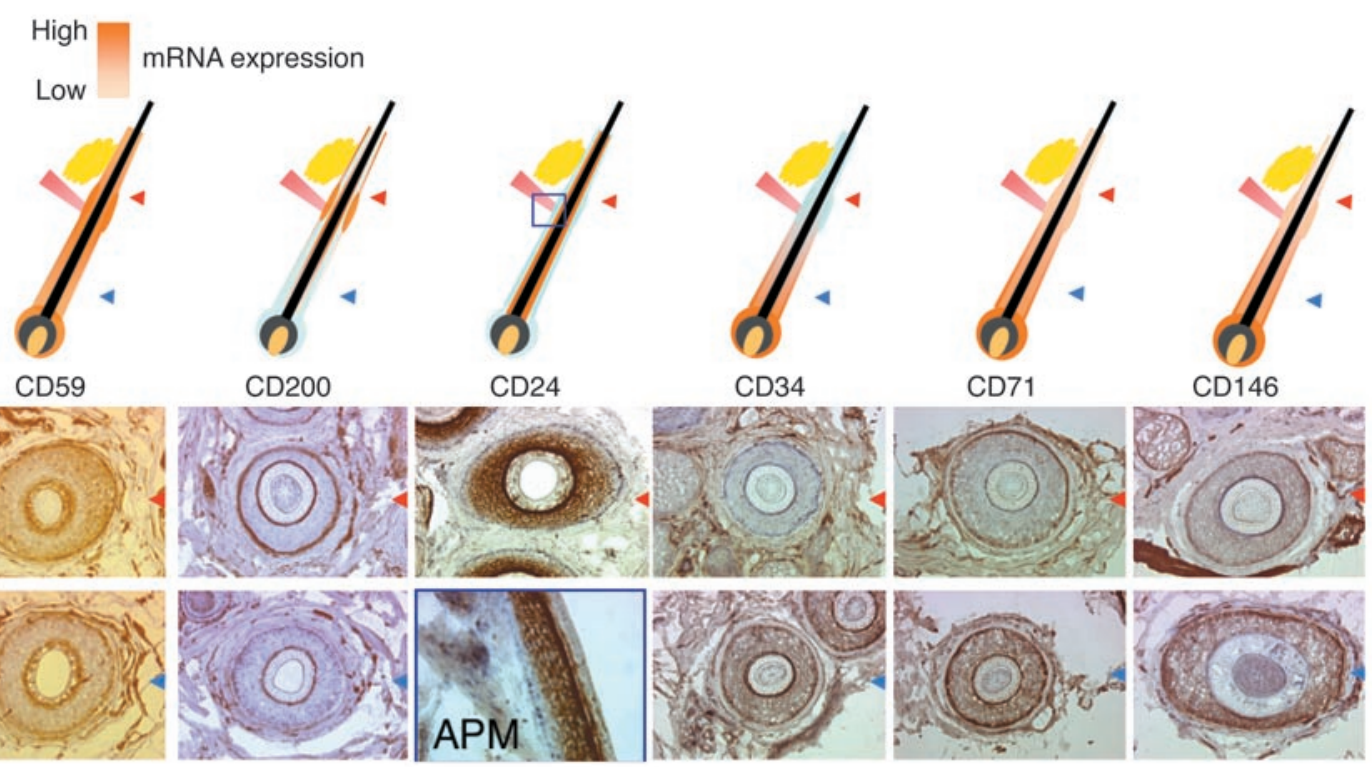

B
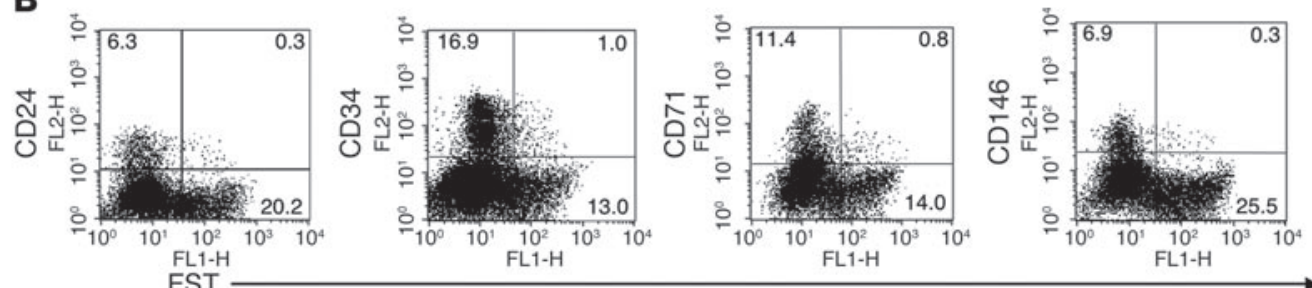

\section{Figure 6}

CD24, CD34, and CD71 together with CD146 were the negative cell surface markers for human hair follicle bulge cells. (A) Upper schemata illustrate the mRNA expression pattern of CD24, CD34, CD71, and CD146 in human hair follicles predicted by GeneChip analysis. The orange gradient indicates the expression intensities. Lower panels demonstrate the staining pattern of each CD marker in transverse sections of different levels of the same follicle. Red and blue arrowheads indicate the levels of bulge and sub-bulge, respectively. Scale bar: 50 um. (B) FACS analysis of mid-follicle cell suspension with anti-CD24, -CD34, -CD71, and -CD146 mAbs and the bulge ORS indicator FST (living 7-AAD-negative cells were gated).

5.71-fold; dChip, 4.71-fold), enhances the local bioavailability of 3,3',5-triiodothyronine, an active form of thyroid hormone (37), and the hair loss associated with hypothyroidism suggests that upregulation of DIO2 may play an important role in supporting human bulge ORS cells. Another upregulated transcript, angiogenic factor ANGPTL2, may also support development of vasculature and nutrition of bulge ORS cells (38).

Many of the transcripts that are underrepresented in bulge ORS cells are involved in cell cycling or DNA replication/repair, such as CDC2, PRC1, and TOP2A. High-level expression of these genes in slow-cycling KSCs would not be expected. Most of the bulge-underrepresented genes were expressed in a gradient that increased from the sub-bulge to the suprabulbar ORS, consistent with the active proliferation that occurs in the lower portion of the anagen follicle.

Upregulation of WNT and TGF $\beta /$ BMP pathways was a common characteristic of human bulge and mouse bulge cells (summarized in Supplemental Tables 1 and 3) (7, 10), supporting our contention that the defined bulge region is also the stem cell niche in human hair follicles. On the other hand, elevation of DIO2 and ANGPTL2 were only observed in human bulge. In addition, a number of genes were divergently regulated in mouse bulge and human bulge. These include latent TGF $\beta$ binding protein 2, FGF18, and, importantly, $C D 34(7,10,11)$. Divergent CD34 expression has also been noted on murine and human hematopoietic stem cells, with high levels expressed on human stem cells and barely detectable levels present on murine hematopoietic stem cells (39). These findings suggest that important structural and/or biological differences between human and mouse bulge ORS may exist.

It has been reported that application of different bioinformatic algorithms to the same microarray data can yield quite different outcomes (40). In fact, we observed that only about $25-40 \%$ of differentially expressed genes were detected by both algorithms (MASv5.0 and dChip 1.3; Supplemental Figure 1). Combining different algorithms to analyze microarray data (10) may provide greater confidence that detected differences are meaningful. However, such an approach does risk missing important biological findings. For example, with the exception of CD146, none of the bulge-positive or -negative markers that we ultimately utilized were predicted when both algorithms were combined. By reanalyzing microarray data and focusing on membrane proteins, we eventually found CD200 as the best positive marker and CD24, CD34, CD71, and CD146 as useful negative selection markers for human bulge ORS cells. 
A
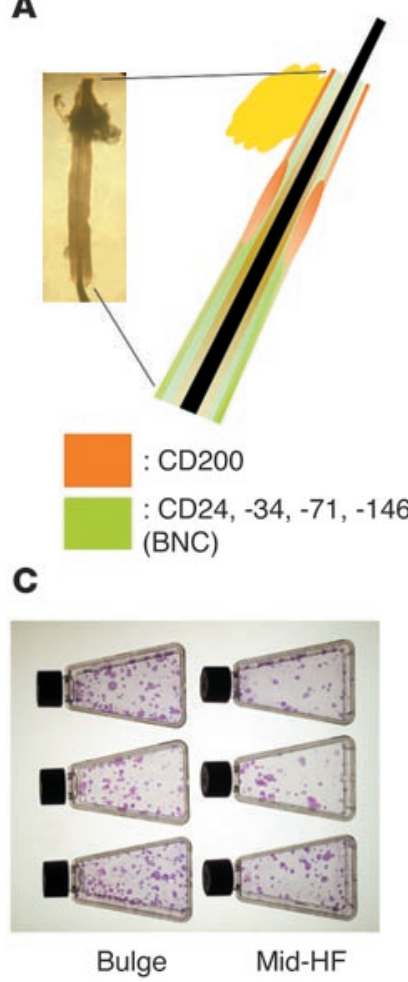

B

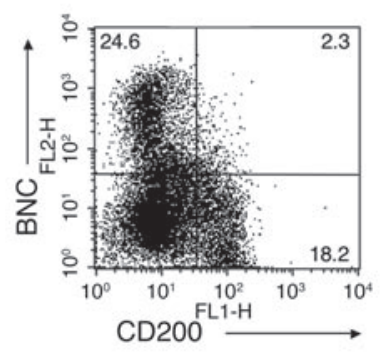

D

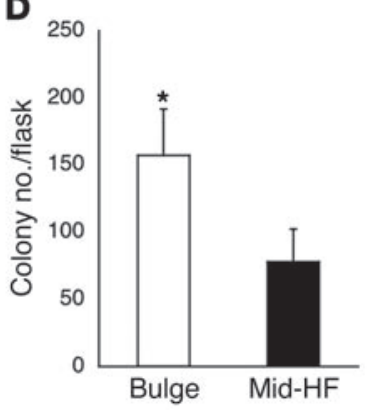

Expression of CD200 has previously been detected in the mouse hair follicle ORS $(10,41)$, but to our knowledge, its expression in human hair follicles has never been described. Microarray analysis of mouse bulge cells suggested the upregulation of CD200 at the mRNA level (10). However, at the protein level, CD200 was predominantly detected in the outermost layer of ORS throughout the length of the mouse hair follicle and did not localize in the bulge area (41). CD200 is a type-1 transmembrane glycoprotein that delivers a negative immunoregulatory signal though the CD200 receptor (CD200R) (42, 43). CD200-CD200R interaction is thought to play a role in restricting tissue-specific autoimmunity (44). When CD200-/- mouse skin was grafted onto wild-type mice, dense inflammation developed around grafted hair follicles and led to hair loss, suggesting that CD200 may be involved in maintaining immune tolerance or regulating some other aspect of inflammation (41). Expression of CD200 by human bulge cells may play a crucial role in affording immune privilege to KSCs and other supporting cells. Presence of CD200 may also explain why the bulge area is well protected from inflammation that impinges on follicles in alopecia areata, an autoimmune disease that results in hair loss. CD200 mRNA has also been detected in human foreskin epidermis, but the presence of CD200 protein has not been demonstrated (41). We have identified a small subpopulation $(2 \%)$ of CD $200^{+} \mathrm{CD}^{4} 5^{-} \mathrm{c}-\mathrm{Kit}^{-}$ cells in human neonatal foreskin (data not shown), and characterization of these cells is in progress.

Among bulge-negative markers, CD24 may be especially important for the bulge cell enrichment because it facilitates removal of CD200-positive cells that are also present in the companion layer. CD24 is a glycoprotein that is thought to be involved in cell adhesion and signaling in lymphocytes or neural cells and that has been reported to be expressed in human follicle ORS and inter-

\section{Figure 7}

Selection for $\mathrm{CD} 200^{+}$highly clonogenic living human hair follicle bulge cells. (A) The expression pattern of CD200 (orange) and CD24, CD34, CD71, and CD146 (light green) in the mid-portion of the human hair follicle. Antibodies against CD24, CD34, CD71, and CD146 constituted the BNC. The panel on the upper left demonstrates an example of the mid-portion of a hair follicle freshly isolated from a human scalp sample. (B) FACS analysis of mid-follicle cell suspension with anti-CD200 antibody and BNC (living 7-AAD-negative cells were gated). (C and D) Isolated $\mathrm{CD} 200^{\text {hi }} \mathrm{BNChi}$ bulge cells formed a greater number of colonies than mid-follicle cells ( ${ }^{*} P<0.001$ ), when equivalent numbers of living cells were seeded onto irradiated NIH 3T3 cells. Representative data from 3 individual experiments are shown in $\mathbf{C}$.

follicular epidermis (45). CD24-positive epidermal cells were not clonogenic (45), supporting the use of this marker for negative selection in bulge cell preparation. In addition, the observation that CD24-negative cells in breast cancer epithelium contained cancer stem cells (46) is consistent with downregulation of CD24 in the hair follicle stem cell niche.

Enrichment of human KSCs by isolation of CD200hi BNC lo bulge cells was supported by the following observations. First, CD200hi cells represented a fraction of $\alpha 6$ integrin ${ }^{\text {hi }}$ cells in mid-follicle suspension. Consequently, CD200 ${ }^{\text {hi }} \mathrm{BNC}^{\text {lo }}$ bulge cells should be $\alpha 6$ integrin ${ }^{\text {hi }} \mathrm{CD} 71^{\mathrm{lo}}$, a cell-surface phenotype previously suggested for putative KSCs (25). Second, isolated bulge cells were relatively small and round, additional proposed KSC characteristics $(25,47)$. Finally, isolated bulge cells demonstrated high colony-forming efficiency $(10,11,15)$.

The isolated CD200hi ${ }^{\text {BNClo }}$ cells exhibited a 2 -fold increase in colony-forming efficiency compared with mid-follicle cells, a seemingly modest enrichment of clonogenic KSCs. However, mid-follicle suspensions were generated from mechanically dissected middle portions of hair follicles that were subsequently trypsinized, and bulge ORS cells are already enriched in this population, representing about $10-20 \%$ of all living cells in mid-follicle suspensions. Efficient generation of single-cell suspensions from intact hair follicles without compromising cell viability has not yet been possible. Thus, the colony-forming efficiencies of CD200 ${ }^{\text {hi }} \mathrm{BNC}^{\text {lo }}$ bulge cells cannot be compared directly with those of hair follicle keratinocytes.

New insights into hair follicle biology that result from our work may also facilitate development of novel therapies for important dermatologic disorders. Accumulation of human hair follicle microarray data may also lead to an understanding of how upregulated gene products such as DKK3, WIF1, and FST could be used for the maintenance of isolated bulge cells ex vivo, an important requirement for regenerative medicine. Growth factors that are upregulated in suprabulbar ORS (e.g., FGF18 and PDGFC) may enhance hair shaft growth and may have therapeutic efficacy in alopecia. Thus, the precise transcription profiles of human ORS subsets obtained in this study, together with the cell surface markers of bulge ORS cells that we identified, should be useful tools for studies of human hair follicles and epidermal stem cell biology as well as regenerative medicine.

\section{Methods}

Human scalp samples. For N-LCM-microarray study, 5-mm punch biopsy samples ( $n=5,1$ sample per healthy volunteer) were taken from the temporal region of the scalp and immediately embedded into OCT compound 
(Sakura Finetek Co.) at $-80^{\circ} \mathrm{C}$ until sectioned. For mid-follicle suspension, surgical scalp specimens were kept at $4^{\circ} \mathrm{C}$ in DMEM (Invitrogen Corp.) containing antibiotics (Cambrex) for no more than 3 days. Protocols for processing human specimens were approved by the Institutional Review Board of the National Cancer Institute.

Detection of LRCs in human hair follicles. To define the precise distribution of LRCs in human anagen follicles, full-thickness human scalp tissues were grafted onto nude mice and labeled with BrdU. All animal experiments were approved by the Animal Care and Use Committee of the National Cancer Institute. Three weeks after grafting, 2 ALZET osmotic pumps (model 1002; DURECT) were implanted subcutaneously every 2 weeks, and $100 \mu \mathrm{M}$ BrdU solution was delivered continuously for 4-6 weeks at $0.4 \mathrm{mg} / \mathrm{d}$ (total dose, $11.2-16.8 \mathrm{mg}$ ). The grafts $(n=4)$ were harvested after a 10 - to 12 -week chase period. Frozen serial transverse sections were stained for BrdU with anti-BrdU-peroxidase Fab fragments (Roche Diagnostics Corp.) according to previously described techniques (48).

Immunohistochemical staining. To detect the LRC distribution, frozen scalp biopsy sections were defrosted, air dried for 3 hours, and fixed with acetone for 10 minutes at $-20^{\circ} \mathrm{C}$. They were then incubated with a $2: 1$ cocktail of mouse C8/144B mAb (cross-reacts with KRT15; DakoCytomation) and mouse anti-human desmin D33 mAb (DakoCytomation) for 2 hours, followed by staining with the EnVision peroxidase system (DakoCytomation). To confirm microarray results, we used mouse anti-human FST and rat anti-mouse/human FZD1 mAbs (clone 85918 and clone 162531; R\&D Systems), mouse anti-human PHLDA1 mAb (clone 2X113; Novus Biologicals Inc.), goat anti-human WIF1, DKK3, and EDNR polyclonal Abs (crossreactive to type A and B) (sc-15666, sc-14959, and sc-21194; Santa Cruz Biotechnology Inc.), mouse anti-human CD146 (clone P1H12; Chemicon International), CD24, CD34, CD71 (clone ML5, 563, M-A712; BD Biosciences - Pharmingen), and CD59, CD200 mAbs (clone MEM-43, MRC OX104; Serotec). Human scalp sections were air dried for 1 hour, fixed with acetone at $-20^{\circ} \mathrm{C}$, and incubated with primary antibodies (diluted 1:10-1:500) for 1.5-4 hours at room temperature or overnight at $4^{\circ} \mathrm{C}$. Subsequent reactions were performed using a mouse or goat ImmunoCruz staining system (Santa Cruz Biotechnology Inc.) with DAB as an HRP substrate. Slides were mounted with Permount or Crystal/Mount (Biomeda Corp.) and photographed with a microscope (Axioskop; Zeiss) connected to a digital camera system (DEL-750; Optronics). All experiments were performed at least twice using specimens from different individuals.

Transverse serial sectioning for LCM. Scalp biopsy samples $(n=5)$ were embedded into OCT compound and, beginning on the subcutaneous side, $8-\mu \mathrm{m}$ frozen serial transverse sections were prepared from each sample using a cryostat thoroughly wiped with RNase AWAY (Molecular BioProducts) and $100 \%$ ethanol. Collection of tissue slices started when the majority the hair follicles on the section were at the suprabulbar level. With every second tissue slice collected, 100 serial sections encompassed the suprabulbar area to the upper isthmus of hair follicles.

$N-L C M$ and RNA isolation. A N-LCM approach developed by Wong et al. (22) was modified to avoid mRNA degradation during LCM. Every fifth section was stained with C8/144B and D33 mAbs (guiding sections), while the 4 intervening sections were kept at $-80^{\circ} \mathrm{C}$ to preserve RNA integrity. Guiding sections were individually photographed to generate serial navigation maps for LCM. Each individual follicle was traced from the suprabulbar to upper isthmus, and the anatomical level of each anagen follicle was determined based on the staining pattern. When a hair follicle on 2 consecutive guiding sections satisfied the bulge criteria, the 4 intervening sections of the same follicle were used to isolate bulge cells.

In the first set of N-LCM experiments $(n=3)$, the 10 serial slides with the highest number of bulge-containing hair follicles (19-30 follicles/slide) were selected using the navigation maps, and the defined bulge ORS cells on unstained sections (8 sections) were LCM captured from selected follicles (Figure 2C). The cells in the outermost layer of ORS just below the insertion point of arrector pili muscle (sub-bulge ORS) were also collected from the same selected hair follicles.

In the second N-LCM experiment, the anatomical location of the serial section was determined by the level represented by the majority of follicles on the stained guiding sections, and the desired ORS subsets were captured from the 4 intervening sections ( $40-50$ follicles/slide). ORS cell populations collected were: those of the outermost layer of ORS on the upper border of bulge (upper-bulge ORS); the main body of bulge; the subbulge ORS (as defined above); the outermost layer of ORS just above the bulb (suprabulbar ORS); and the inner layers of ORS at the bulge level (inner-bulge ORS) (Figure 2A).

All N-LCM sections were stained with HistoGene LCM frozen section staining kit (Arcturus) according to the manufacture's protocol and kept desiccated until used. The target ORS cells were captured with PixCell 11 system using Capsure LCM Macro caps (Arcturus). The laser spot size was $7.5 \mu \mathrm{m}$. Pulse power was $75-100 \mathrm{~mW}$, and pulse width was $1.0-1.8 \mathrm{~ms}$, depending on the LCM condition. Total RNA was isolated from the captured cells by Picopure RNA isolation kit (Arcturus) and DNase digestion (QIAGEN).

Microarray generation. RNA quality and quantity were assessed with an Agilent 2100 bioanalyzer and a RNA 6000 Pico LabChip kit (Agilent Technologies). We used a T7-primer-based 2-round linear RNA amplification protocol: GeneChip Eukaryotic Small Sample Target Labeling Assay Version II (https://www.affymetrix.com/support/downloads/manuals/expression_s2_manual.pdf, equivalent to the GeneChip Two-Cycle cDNA Synthesis kit; Affymetrix). Fifteen micrograms of biotin-labeled cRNA from each individual sample was fragmented and first hybridized with Affymetrix T3 test array for quality assessment and then rehybridized to an Affymetrix high-density oligonucleotide array for human genes (HG-U133A containing 22,283 probe sets). All arrays were stained, washed, and scanned following the manufacturer's protocol.

Microarray data analysis. To identify the genes differentially expressed in bulge ORS, we performed 2-step data analysis (Supplemental Figure 1). First, we analyzed the 3 pairs of GeneChips obtained by the first N-LCM experiment. This analysis enabled us to generate the list of genes differentially expressed between the bulge and sub-bulge ORS cells. To ensure statistical rigidity, scanned data were analyzed with different statistical algorithms: MASv5.0 and dChip 1.3 (http://www.dchip.org, Wong Lab, Harvard University). In MAS analysis, chip files (.CHP files) for individual ORS populations were created according to the following parameters: target signal scaling 150, Alpha1 0.05, Alpha2 0.065, Tau 0.015. Then, setting sub-bulge ORS chips as the baseline, a bulge expression analysis file for each pair was generated. The parameters for this expression analysis were Gamma1H 0.0045, Gamma1L 0.0045, Gamma2H 0.006, Gamma2L 0.006, Perturbation 1.1. Probe sets were defined as differentially expressed between bulge and sub-bulge ORS when the probe set was detected as increased or decreased in all bulge ORS chips compared with sub-bulge ORS chips by expression analysis or when detected as expressed (present call) exclusively in the bulge or sub-bulge ORS chips. The fold change for each probe set was calculated by taking the average of the ratios of signal intensities between individual bulge and sub-bulge ORS chips pairs. We set the cutoff average fold change as at least 1.3. In dChip analysis, Affymetrix cell files (.CEL files) were normalized and calculated for MBEI. Then, differentially expressed genes between bulge ORS chip (experimental [E]) and sub-bulge (baseline [B]) were identified by the comparison analysis in the software. In this analysis, the filtering criterion for this comparison were (a) fold change (E/B or B/E) $\geq 1.3$, (b) $P$ value for paired Student's $t$ test $<0.05$. The list of genes detected as 
differentially expressed both by MAS and dChip were obtained by compiling the results of 2 analyses. Then, individual genes were evaluated for their RNA expression pattern in different follicle regions by a second $\mathrm{N}$-LCM data set analysis. Upper-bulge, bulge, inner-bulge, sub-bulge, and suprabulbar GeneChips were normalized by MAS according to the described parameters. Genes that had the highest expression in either inner-bulge or suprabulbar ORS or in either upper-bulge or inner-bulge chips were removed from the bulge upregulated or downregulated gene list, respectively, to obtain the final list of the genes specifically up- or downregulated in bulge ORS. The function and ontology of listed genes were assessed by Entrez Gene (http://www.ncbi.nlm.nih.gov/entrez/ query.fcgi) linked with GOA@EBI (http://www.ebi.ac.uk/GOA/). The raw chip data files are available at http://www.ncbi.nlm.nih.gov/geo/ query/acc.cgi? acc $=$ GSE3419.

Preparation of cell suspensions from the mid-portion of buman hair follicles (mid-follicle suspensions). Scalp tissue (approximately 5-6 $\mathrm{cm}^{2}$ ) was washed with PBS 3 times to remove clots. Hairs were shaved, and the epidermis and subcutaneous fat were removed using a scalpel. The remaining dermal tissue contained the mid-portion of hair follicles between the isthmus and suprabulbar area. The tissue was cut into several pieces and incubated overnight in 1:1 mixture of HBSS (Invitrogen Corp.) and dispase (BD Biosciences) at $4^{\circ} \mathrm{C}$. After washing with PBS, individual follicles were gently pushed out the scalp with fine forceps. Isolated follicles were incubated with $0.05 \%$ trypsin (USB) at $37^{\circ} \mathrm{C}$ for $45 \mathrm{~min}$ utes and neutralized by an equivalent volume of PBS containing $0.05 \%$ DNase (Sigma-Aldrich) $/ 5 \%$ FBS and HBSS. After filtering the suspension 2 times through $100 \mu \mathrm{m}$ nylon mesh filters, mid-follicle cells were collected by centrifuging at $200 \mathrm{~g}$ for 5 minutes and resuspending in PBS containing 5\% FBS (mid-follicle suspension).

FACS analysis of mid-follicle suspensions. Unless noted, FACS analysis of the mid-follicle suspension utilized the same mAbs described above for immunohistochemistry. Hair follicle cells were incubated with primary antibodies for 20 minutes at $4{ }^{\circ} \mathrm{C}$ and washed. If primary antibodies were not directly conjugated, hair follicle cells were incubated with secondary antibodies such as the FITC-conjugated mouse anti-rat IgG1/2a mAb (BD Biosciences - Pharmingen) or PE-conjugated rat anti-mouse IgG1 or IgG2a+b mAb (BD Biosciences - Immunocytometry Systems) for another 20 minutes. For double staining with bulge markers, PE-stained cells were fixed and permeabilized with Cytofix/Cytoperm buffer (BD Biosciences - Pharmingen), washed and incubated with Alexa Fluor 488-conjugated mouse anti-human KRT15 (clone LHK15; Lab Vision Corp.) or FST antibodies for 30 minutes at room temperature. Zenon mouse IgG2a labeling kit (Invitrogen Corp.) was used for the conjugation of Alexa Fluor 488 to those antibodies. Mouse anti-human CD24 (clone SN3; Serotec) and CD71 (clone DF1513; Lab Vision Corp.) mAbs were used for this double staining analysis. Purified FITC- or PE-conjugated rat IgG2a (CALTAG Laboratories), mouse IgG1, and mouse IgG2a (BD Biosciences) were used as the isotype controls. The stained follicle cells were incubated with 7-AAD (BD Biosciences - Pharmingen) and analyzed with a FACSCalibur flow cytometer equipped with CellQuest software (BD Biosciences) for 10,000-25,000 events.

Isolation of bulge cells with magnetic beads systems. Two magnetic beads systems were combined to isolate bulge ORS cells from the mid-follicle suspension. First, hair follicle cells were stained with the cocktail of PE- conjugated anti-human CD24, CD34, CD71, and CD146 antibodies (BNC) for 20 minutes at $4^{\circ} \mathrm{C}$. After washing, follicle cells were incubated with anti-PE microbeads (Miltenyi Biotec) for 25 minutes at $4{ }^{\circ} \mathrm{C}$. Then, PE-positive non-bulge cells were removed with the magnetic separations using mini-MACS MS columns (Miltenyi Biotec). The removal procedures were repeated 3-5 times to ensure maximum depletion. Next, midfollicle cells were incubated with purified anti-human CD200 mouse $\mathrm{mAb}$ at $4^{\circ} \mathrm{C}$ for 20 minutes, washed, and incubated with Dynabeads M-450 sheep anti-mouse IgG magnetic beads (Dynal Biotech) at $4{ }^{\circ} \mathrm{C}$ for 30 minutes with tilting. Then, positive selection was performed with MPC-L magnetic particle concentrator (Dynal Biotech) to obtain CD200-positive cells. CD59-positive cells were similarly collected as the positive selection control.

Colony-forming assay. To determine whether $\mathrm{CD} 200^{+}$hair follicle cells had a higher colony-forming efficiency than control mid-follicle suspension cells, we performed an in vitro colony-forming assay originally described by Rheinwald and Green (49). Equivalent numbers of living $\mathrm{CD}^{200}{ }^{+} \mathrm{BNC}^{-}$bulge cells and mid-follicle cells $(5,000$ cells/flask) were prepared and seeded into T-25 flasks (Corning) onto a lethally irradiated NIH 3T3 cell feeder layer. Hair follicle cells were cultured in a 3:1 mixture of DMEM and Ham's F12 medium (Invitrogen Corp.) supplemented with $10 \%$ FBS, $180 \mu \mathrm{M}$ adenine, $5 \mu \mathrm{g} / \mathrm{ml}$ insulin, $0.5 \mu \mathrm{g} / \mathrm{ml}$ hydrocortisone, $0.1 \mathrm{nM}$ cholera toxin (Sigma-Aldrich), and $10 \mathrm{ng} / \mathrm{ml}$ epidermal growth factor (Invitrogen Corp.) for 2 weeks. The colonies were fixed with paraformaldehyde (Electron Microscopy Sciences) and stained with the 1:1 mixture of Rhodamine B and Nile blue sulfate solution (SigmaAldrich), and the number of colonies was counted for each individual flask and analyzed with Excel software (version 11.0 for Macintosh; Microsoft). Experiments were performed in triplicate and repeated 3 times, using scalp samples from different individuals.

Statistics. For this assay, 2-tailed Student's $t$ test was used. A $P$ value less than 0.05 was considered statistically significant.

\section{Acknowledgments}

We thank Maria C. Turner, Laura Musse, and Susan Boohner of the Dermatology Branch, Center for Cancer Research (CCR), National Cancer Institute (NCI), NIH, for their help in the volunteer recruitment and scalp biopsies; and Leonard C. Sperling of the Uniformed Services University of the Health Sciences for many helpful discussions and suggestions. We also thank Jana Koeppl-Ritter and all the staff of the Center for Cosmetic Surgery for their help in sample collection. This research was supported by the Intramural Research Program of the NIH, NCI, CCR. M. Ohyama received financial support from the Uehara Memorial Foundation.

Received for publication June 22, 2005, and accepted in revised form October 11, 2005.

Address correspondence to: Jonathan C. Vogel, Dermatology Branch, Center for Cancer Research, National Cancer Institute, National Institutes of Health, Building 10 Room 12N238, 10 Center Drive, MSC 1908, Bethesda, Maryland 20892, USA. Phone: (301) 496-9002; Fax: (301) 496-5370; E-mail: jonvogel@mail.nih.gov.
1. Paus, R., and Cotsarelis, G. 1999. The biology of hair follicles. N. Engl. J. Med. 341:491-497.

2. Fuchs, E., Merrill, B.J., Jamora, C., and DasGupta, R. 2001. At the roots of a never-ending cycle. Dev. Cell. 1:13-25.

3. Cotsarelis, G., Sun, T.T., and Lavker, R.M. 1990. Label-retaining cells reside in the bulge area of pilosebaceous unit: implications for follicular stem cells, hair cycle, and skin carcinogenesis. Cell. 61:1329-1337.

4. Bickenbach, J.R., McCutecheon, J., and Mackenzie, I.C. 1986. Rate of loss of tritiated thymidine label in basal cells in mouse epithelial tissues. Cell Tissue Kinet. 19:325-333.
5. Morris, R.J., and Potten, C.S. 1999. Highly persistent label-retaining cells in the hair follicles of mice and their fate following induction of anagen. J. Invest. Dermatol. 112:470-475.

6. Taylor, G., Lehrer, M.S., Jensen, P.J., Sun, T.T., and Lavker, R.M. 2000. Involvement of follicular stem cells in forming not only the follicle but also the 
epidermis. Cell. 102:451-461.

7. Tumbar, T., et al. 2004. Defining the epithelial stem cell niche in skin. Science. 303:359-363.

8. Montagna, W. 1962. The structure and function of skin. Academic Press. New York, New York, USA. 454 pp.

9. Oshima, H., Rochat, A., Kedzia, C., Kobayashi, K., and Barrandon, Y. 2001. Morphogenesis and renewal of hair follicles from adult multipotent stem cells. Cell. 104:233-245.

10. Morris, R.J., et al. 2004. Capturing and profiling adult hair follicle stem cells. Nat. Biotechnol. 22:411-417

11. Blanpain, C., Lowry, W.E., Geoghegan, A., Polak, L., and Fuchs, E. 2004. Self-renewal, multipotency, and the existence of two cell populations within an epithelial stem cell niche. Cell. 118:635-648.

12. Akiyama, M., Dale, B.A., Sun, T.T., and Holbrook, K.A. 1995. Characterization of hair follicle bulge in human fetal skin: the human fetal bulge is a pool of undifferentiated keratinocytes. J. Invest. Dermatol. 105:844-850

13. Lyle, S., et al. 1998. The C8/144B monoclonal antibody recognizes cytokeratin 15 and defines the location of human hair follicle stem cells. J. Cell Sci. 111:3179-3188.

14. Trempus, C.S., et al. 2003. Enrichment for living murine keratinocytes from the hair follicle bulge with the cell surface marker CD34.J. Invest. Dermatol. 120:501-511.

15. Rochat, A., Kobayashi, K., and Barrandon, Y. 1994 Location of stem cells of human hair follicles by clonal analysis. Cell. 76:1063-1073.

16. Moll, I. 1996. Differential epithelial outgrowth of plucked and microdissected human hair follicles in explant culture. Arch. Dermatol. Res. 288:604-610.

17. Xu, X., Lyle, S., Liu, Y., Solky, B., and Cotsarelis, G 2003. Differential expression of cyclin D1 in the human hair follicle. Am. J. Pathol. 163:969-978.

18. Limat, A., et al. 2003. Organotypic cultures of autologous hair follicle keratinocytes for the treatment of recurrent leg ulcers. J. Am. Acad. Dermatol. 48:207-214.

19. Cotsarelis, G., and Millar, S.E. 2001. Towards a molecular understanding of hair loss and its treatment. Trends Mol. Med. 7:293-301.

20. Ohyama, M., and Vogel, J.C. 2003. Gene delivery to the hair follicle. J. Investig. Dermatol. Symp. Proc. 8:204-206.

21. Fuchs, E., Tumbar, T., and Guasch, G. 2004. Socializing with the neighbors: stem cells and their niche. Cell. 116:769-778.

22. Wong, M.H., Saam, J.R., Stappenbeck, T.S., Rexer, C.H., and Gordon, J.I. 2000. Genetic mosaic analysis based on Cre recombinase and navigated laser capture microdissection. Proc. Natl. Acad. Sci. U. S. A.
97:12601-12606.

23. Khanna, S., Cheng, G., Gong, B., Mustari, M.J., and Porter, J.D. 2004. Genome-wide transcriptional profiles are consistent with functional specialization of the extraocular muscle layers. Invest. Ophthalmol. Vis. Sci. 45:3055-3066

24. Li, C., and Wong, W.H. 2001. Model-based analysis of oligonucleotide arrays: expression index computation and outlier detection. Proc. Natl. Acad. Sci.U.S.A. 98:31-36

25. Tani, H., Morris, R.J., and Kaur, P. 2000. Enrichment for murine keratinocyte stem cells based on cell surface phenotype. Proc. Natl. Acad. Sci. U. S. A. 97:10960-10965.

26. Poblet, E., Jimenez-Acosta, F., and Rocamora, A 1994. QBEND/10 (anti-CD34 antibody) in external root sheath cells and follicular tumors. J. Cutan. Pathol. 21:224-228.

27. Nishimura, E.K., Granter, S.R., and Fisher, D.E. 2005. Mechanisms of hair graying: incomplete melanocyte stem cell maintenance in the niche. Science. 307:720-724.

28. Narisawa, Y., Hashimoto, K., Nakamura, Y., and Kohda, H. 1993. A high concentration of Merkel cells in the bulge prior to the attachment of the arrector pili muscle and the formation of the perifollicular nerve plexus in human fetal skin. Arch. Dermatol. Res. 285:261-268.

29. Virador, V., et al. 2001. Production of melanocytespecific antibodies to human melanosomal proteins: expression patterns in normal human skin and in cutaneous pigmented lesions. Pigment Cell Res. 14:289-297.

30. Yuen, T., Wurmbach, E., Pfeffer, R.L., Ebersole, B.J., and Sealfon, S.C. 2002. Accuracy and calibration of commercial oligonucleotide and custom cDNA microarrays. Nucleic Acids Res. 30:e48.

31. Andl, T., Reddy, S.T., Gaddapara, T., and Millar, S.E. 2002. WNT signals are required for the initiation of hair follicle development. Dev. Cell. 2:643-653.

32. Huelsken, J., Vogel, R., Erdmann, B., Cotsarelis, G., and Birchmeier, W. 2001. $\beta$-Catenin controls hair follicle morphogenesis and stem cell differentiation in the skin. Cell. 105:533-545.

33. Van Mater, D., Kolligs, F.T., Dlugosz, A.A., and Fearon, E.R. 2003. Transient activation of beta -catenin signaling in cutaneous keratinocytes is sufficient to trigger the active growth phase of the hair cycle in mice. Genes Dev. 17:1219-1224.

34. Kobielak, K., Pasolli, H.A., Alonso, L., Polak, L., and Fuchs, E. 2003. Defining BMP functions in the hair follicle by conditional ablation of BMP receptor IA. J. Cell Biol. 163:609-623.

35. Nakamura, M., et al. 2003. Control of pelage hair follicle development and cycling by complex interactions between follistatin and activin. FASEB J.
17:497-499.

36. Toyoshima, Y., et al. 2004. TDAG51 mediates the effects of insulin-like growth factor I (IGF-I) on cell survival. J. Biol. Chem. 279:25898-25904.

37. Kester, M.H., et al. 2004. Iodothyronine levels in the human developing brain: major regulatory roles of iodothyronine deiodinases in different areas. J. Clin. Endocrinol. Metab. 89:3117-3128.

38. Oike, Y., Yasunaga, K., and Suda, T. 2004. Angiopoietin-related/angiopoietin-like proteins regulate angiogenesis. Int. J. Hematol. 80:21-28.

39. Osawa, M., Hanada, K., Hamada, H., and Nakauchi, H. 1996. Long-term lymphohematopoietic reconstitution by a single CD34-low/negative hematopoietic stem cell. Science. 273:242-245.

40. Yang, P., et al. 2004. Study design considerations in clinical outcome research of lung cancer using microarray analysis. Lung Cancer. 46:215-226.

41. Rosenblum, M.D., et al. 2004. Expression of CD200 on epithelial cells of the murine hair follicle: a role in tissue-specific immune tolerance? J. Invest. Dermatol. 123:880-887.

42. Wright, G.J., et al. 2000. Lymphoid/neuronal cell surface OX2 glycoprotein recognizes a novel receptor on macrophages implicated in the control of their function. Immunity. 13:233-242.

43. Wright, G.J., et al. 2003. Characterization of the CD200 receptor family in mice and humans and their interactions with CD200. J. Immunol. 171:3034-3046

44. Barclay, A.N., Wright, G.J., Brooke, G., and Brown, M.H. 2002. CD200 and membrane protein interactions in the control of myeloid cells. Trends Immunol. 23:285-290.

45. Magnaldo, T., and Barrandon, Y. 1996. CD24 (heat stable antigen, nectadrin), a novel keratinocyte differentiation marker, is preferentially expressed in areas of the hair follicle containing the colonyforming cells. J. Cell Sci. 109:3035-3045.

46. Al-Hajj, M., Wicha, M.S., Benito-Hernandez, A., Morrison, S.J., and Clarke, M.F. 2003. Prospective identification of tumorigenic breast cancer cells. Proc. Natl. Acad. Sci. U. S. A. 100:3983-3988.

47. Jones, P.H., and Watt, F.M. 1993. Separation of human epidermal stem cells from transit amplifying cells on the basis of differences in integrin function and expression. Cell. 73:713-724.

48. Terunuma, A., Jackson, K.L., Kapoor, V., Telford, W.G., and Vogel, J.C. 2003. Side population keratinocytes resembling bone marrow side population stem cells are distinct from label-retaining keratinocyte stem cells. J. Invest. Dermatol. 121:1095-1103.

49. Rheinwald, J.G., and Green, H. 1975. Serial cultivation of strains of human epidermal keratinocytes: the formation of keratinizing colonies from single cells. Cell. 6:331-343. 